\title{
Increased Device Sensitivity
}

National Cancer Institute

\section{Source}

National Cancer Institute. Increased Device Sensitivity. NCI Thesaurus. Code C63078.

Problem with a medical device being more sensitive to an input than intended or expected. 